\title{
Parental influences on children's diets
}

\author{
BY JANE WARDLE \\ Imperial Cancer Research Fund Health Behaviour Unit, Institute of Psychiatry, \\ University of London, London SE5 $8 A F$
}

\section{PAEDIATRIC NUTRITION AND HEALTH}

Nutrition has always been regarded as vital for health, growth and development in the childhood years. The evidence that the development of atherosclerosis begins in childhood (Moller et al. 1994) and that the extent of paediatric atherosclerosis is related to serum lipid levels (Newman et al. 1986), has intensified the focus on paediatric nutrition since it now appears likely that the childhood diet can promote the development of cardiovascular disease.

Information on children's diets suggests that they are no better than, and may be worse than, adults' diets. Soft drinks, sweets, chips and meat products form a major part of most children's diets and for many, the 'McDonalds' meal represents their ideal. Data from the US National Health and Nutrition Examination Survey showed an energy intake pattern in which $36 \%$ of energy was derived from fat and $13 \%$ from saturated fat (Kimm et al. 1990) and there were similar results in the Department of Agriculture's Continuing Surveys of Food Intakes for children aged 2-5 years (Thompson \& Dennison, 1994). Data from the UK paint a similar picture; in 1983, 3285 British children kept a $7 \mathrm{~d}$ weighed record of all their food and drink. The results showed that fat contributed over $38 \%$ of their energy intake (Committee on Medical Aspects of Food Policy, 1989). In the more recent survey of British $1.5-4$ year olds, fat contributed $35.9 \%$ of their energy intake and saturated fats $16 \cdot 2 \%$ of intake (Gregory et al. 1995).

There have been fewer studies on the intake of fruit and vegetables, dietary fibre or vitamins, but such data as are available point to inadequate intakes. Basch et al. (1994) collected several $24 \mathrm{~h}$ dietary recalls over 3 years for 308 preschool children. Intakes of fruits and vegetables were based on criteria from the National Cancer Institute's 5-a-day programme (Havas et al. 1994). The average number of servings was 2.8 (1.8 servings of fruit, one serving of vegetables). Children in the highest quintile had substantially higher intakes of several vitamins and minerals as well as fibre, but no difference in fat as a proportion of energy. Results from $3 \mathrm{~d}$ food diaries, recorded as part of a study of ninety-one British families with 9-11-year-old children (the Family Diet Study; $\mathrm{J}$. Wardle, unpublished results), showed average intakes of $191 \mathrm{~g}$ daily of fruit and vegetables, with only $5 \%$ of children exceeding the recommended intake of $400 \mathrm{~g}$.

\section{ESTABLISHING EATING HABITS}

The longer-term health consequences of a poor diet in childhood provide one reason for concern about what children eat. The other reason stems from the idea that food habits and preferences are developed and established in childhood; thus, liking for, and consumption of, fatty, salty, sugary, energy-dense foods in the early years could be established as a lifelong pattern. Two assumptions underlie the idea of 'establishing 
healthy habits in childhood'. The first is that dietary habits can be established (as opposed to children's eating merely being controlled, where possible, by parents) and the second is that the habits of childhood persist into adulthood. The evidence for these two assumptions is discussed below.

The principal source of information about the development of eating habits has been observation of human eating patterns. People within a culture eat broadly similar foods, but there are profound differences across cultures (Rozin, 1990). Assuming that there are not fundamental cultural differences in taste sensitivity, then experience with, and attitudes to, foods must account for variation. There are also specific preferences for bitter, slimy, or hot foods in most cultures (e.g. coffee, oysters, chilli) which are rarely acquired until adulthood. Learning to like these initially unpalatable substances may be part of socialization. The other source of information about children's food choices is laboratory studies. There has been particular attention to the effect of exposure (or mere exposure as it is often called) on liking. The evidence strongly suggests that exposure both enhances liking and focuses it. Repeated exposure to a novel food increases liking for it and may decrease liking for another variant of the exposed food (Birch \& Marlin, 1982). Familiarity may be a positive feature because in the past novelty would have been associated with the possibility that the food was not safe to eat, whereas a food which has been eaten before without adverse consequences becomes safe. Whatever the mechanism, these results suggest that controlling what children eat should influence what they like and providing children with a healthier diet is likely, all other things being equal, to increase their liking for healthy foods. Of course, all other things are not equal and there are many factors which could dwarf the impact of parental attempts to serve healthy foods. Advertising is usually directed towards promoting consumption of the very foods which parents are attempting to limit. Increasingly, children select their own foods in the home in a 'grazing' style, and children's own choices are likely to be less healthy than their parents' choices would be on their behalf (Klesges et al. 1991). Peer pressure and modelling, also, can promote liking for less healthy foods which are popular among that age-group (Birch, 1987). Finally, biological factors, i.e. innate taste and texture preferences, can militate against healthy choices. Sweetness, saltiness and fat content contribute significantly to the acceptability of foods. Post-ingestional effects of foods, also, can modify liking with more energy-dense foods being preferred (Birch et al. 1990; Johnson et al. 1991). In that case, sweet and fatty foods could have double advantage; they taste good the first time, and their appeal grows.

\section{PERSISTENCE OF CHILDHOOD EATING HABITS}

The second assumption of the habit model is that childhood habits persist into adult life. In fact, there is comparatively little evidence that dietary habits persist, but this is principally because there are so few longitudinal studies. As part of the Minnesota Heart Health Program a cohort of children was surveyed annually (Kelder et al. 1994). Dietary behaviour was assessed by asking the children to select, from eighteen food pairs, 'the one food you would usually eat when you had the choice'. 'Tracking' (i.e. preservation of relative position) was evaluated by assigning children to one of five categories based on the numbers of healthy choices at the year-1 assessment and looking at the mean number of healthy choices within each group for each subsequent year. The results indicated a gradual increase in healthy choices with time but no real change in the rankings of the 
five groups; so children who made the fewest healthy choices in 1983, also made fewest in 1989 , and those who made most healthy choices continued to make the most. The approximately parallel tracks of the five groups suggested that none was especially susceptible to other environmental or biological effects and that dietary habits persist. However, these results could be interpreted in terms of tracking of liking, rather than choice, in view of the wording of the question, in which case the field is still wide open concerning stability of actual dietary behaviour.

There is also evidence for tracking of the physiological variables such as blood lipids or body fatness, on which there is substantial dietary influence. Both the Bogalusa Heart Study (Berenson et al. 1989) and the Muscatine Study (Lauer \& Clarke, 1990) found strong tracking for lipids and blood pressure. A study of over 800 Finnish children (Porkka et al. 1994) had complete data on lipids over a 12-year period. Correlations between the 1980 and 1992 results ranged from 0.33 for triacylglycerols to between 0.48 and 0.58 for total, high-density-lipoprotein (HDL)- and low-density-lipoprotein (LDL)cholesterol. Obesity also shows signs of tracking; data from the Bogalusa Heart Study found correlations between body mass index (BMI) at baseline and 8-year follow-up ranging between 0.54 and 0.77 (Freedman et al. 1987), with higher correlations for children who were older at the time of the first assessment.

\section{PARENTAL INFLUENCES ON CHILDREN'S NUTRITION}

Investigations of parental influences in children's nutrition are few and far between, despite the widespread assumption that parents influence both their children's eating behaviour and their attitudes towards food. Two main methodological approaches have been used: (1) the investigation of parent-child similarities in preferences, behaviour, knowledge or nutritional status, and (2) studies of how parents attempt to influence their children; these usually being qualitative studies.

\section{PARENT-CHILD CORRELATIONS IN RISK-FACTOR STATUS}

Parent-child similarities in risk-factor status are well established and, indeed, it is a common observation that fatness runs in families. Garn (1986) pointed out that by the age of 17 years, the children of two fat parents were two to three times fatter than the children of two lean parents. Parent-child correlations for skin-folds ranging from $0 \cdot 19$ to 0.21 were reported by Garn et al. (1979). Data from the Princeton School District Study (Khoury et al. 1983) found correlations for BMI ranging from 0.22 for mother-son pairs to 0.29 for father-son and father-daughter pairs. The correlations between parents and adult offspring were lower $(-0.08$ to $0 \cdot 17)$. More recent data from a French family study reported correlations of 0.25 for parent-child correlations for weight (Tiret et al. 1991), and in the National Heart, Lung and Blood Institute Growth and Health Study, there were mother-daughter correlations of a similar magnitude for BMI (Morrison et al. 1994). Comparable levels of parent-child similarity have been reported for cholesterol. In the Princeton Study (Morrison et al. 1982), correlations between parents and paediatric offspring ranged from 0.23 (father-son) to 0.38 (mother-daughter), but results were very variable for parent-adult offspring correlations $(-0.40$ to 0.44$)$. Data from the Growth and Health Study found parent-child correlations between 0.30 and 0.36 for total, HDL- and LDL-cholesterol (Morrison et al. 1994). 
Parent-child similarities can of course point to shared environmental characteristics (e.g. a similar diet) or shared genes. If the effect is principally genetic, then conscious parental guidance may not be directly influencing risk factors. Recent genetic research on obesity fails to find much evidence that shared family environment contributes substantially to the aetiology of obesity; the adoption studies are especially persuasive in indicating that living together (or rather, having been brought up together) does not automatically generate a similarity in body size (Vogler et al. 1995), although there are dissenting voices from this view. In the case of familial lipid resemblances there have been fewer sophisticated genetic studies, but twin research has indicated a substantial genetic contribution, and analyses of spouse correlations (Sackett et al. 1975) show no significant increase in similarity with increased duration of marriage. In the Princeton Study, there were no significant spouse correlations in total cholesterol except in one subgroup of ten subjects (Morrison et al. 1982). These results suggest caution should be exercised in assuming that familial similarities in risk-factor status are attributable to familial similarities in diet.

\section{PARENT-CHILD CORRELATIONS IN DIET}

Parent-child similarities in diet have been evaluated in several studies. Data from the Princeton Study (Laskarzewski et al. 1980) found correlations ranged from 0.21 for energy and carbohydrate, and 0.15 for saturated fat to 0 for cholesterol. Perusse et al. (1988) reported parent-child correlations from 0.25 (for energy intake) to 0.31 for fat intake, in a sample of 375 families who completed a $3 \mathrm{~d}$ dietary record. Data from the Framingham Children's Study (Oliveria et al. 1992) were based on four sets of $3 \mathrm{~d}$ diaries recorded over 1 year. Again parent-child correlations ranged from $0 \cdot 20$ for energy to 0.47 for saturated fat. That a shared family life and a shared household food supply makes a major contribution to the family correlation was supported by the even stronger pattern of correlations for spouses in this study which ranged from 0.39 for energy to 0.56 for saturated fat. There have been few studies reporting data on parent-child similarity in consumption of actual foods (rather than nutrient intakes computed from food records). In the Family Diet Study, data from food frequency questionnaires for mothers and children revealed enormous variability in the parent-child correlation across foods, which suggests that more complex processes are at work in the modern family than simply shared meals.

\section{PARENT-CHILD CORRELATIONS IN PREFERENCES}

In view of the evidence that food intakes, or at least nutrient intakes, show familial aggregation, and that food exposure influences liking, some degree of family similarity in food likes and dislikes might be expected. In fact, the evidence suggests comparatively low parent-child correlations in preferences. In one of the earliest studies, Bryan \& Lowenberg (1958) evaluated similarities between six fathers and their preschool children. The fathers categorized a number of vegetables, fruit and protein foods as liked, accepted or refused and the mother made the same categorization for the child. The father-child correlation in the number of likes in each category ranged from 0 (for protein foods), and 0.06 for fruits to 0.28 for vegetables. Fathers liked more foods overall $(73 v .61 \%)$, especially vegetables $(65 v .41 \%)$ and protein foods $(74 v .61 \%)$, although 
of the twelve most-widely-liked foods, nine were shared by father and child.

Birch (1980) was one of the first to evaluate food liking by testing rather than self-report. Subgroups of parents and children tasted and rated (like, neutral or dislike) fruits, sandwich fillings, vegetables and snacks. A correlation coefficient across all foods was calculated for each parent-child pair. The proportion of correlations which were significant for mother-child pairs was $10 \%$ and for father-child pairs $7 \%$. Correlations were also computed between each child and an unrelated adult, of which $8 \%$ were significant, which suggested that shared genes and family life contributed little over shared culture. Even shared culture promoted little similarity of liking, since $5 \%$ of this large number of correlations would be expected to be 'significant' by chance alone. In a study based on food-preference ratings of college students (still living at home) and their parents (Pliner, 1983), a similar method was used, i.e. computing pair-wise correlations across foods and comparing average correlations in child-parent pairs with average correlations in child-unrelated adult pairs. The mean correlation of 0.25 for parent-child pairs, which was approximately twice that for unrelated pairs $(0 \cdot 11)$, gives some evidence for family resemblance. There was evidence also for stronger similarity for same-sex pairs than for other-sex pairs. Similar findings were reported by Pliner \& Pelchat (1986). In these analyses the family dyad is the unit of analysis, with the resulting correlation indicating whether foods which one member likes, the other also likes, and vice-versa. The problem with this method is that it is susceptible to shared cultural values rather than intra-familial links and compromised by general differences between adults and children concerning the foods which they like or dislike. The alternative method is to examine parent-child similarity by food, investigating whether, for example, mothers who like broccoli tend to have children who like broccoli. Data on five 'heart-healthy' foods showed mother-child correlations ranging from -0.09 to 0.28 , none being significant Weidner et al. (1985). Rozin (1991) in a study of students and their parents, found parent-child correlations ranging from -0.03 to 0.35 over ten foods, illustrating the variability. The average correlation was also substantially lower than the average correlation for aesthetic preferences or values. Similar results were obtained in the Family Diet Study, i.e. a low average correlation and great variability across foods, raising the possibility of different processes at work for different foods or food types.

\section{COGNITIVE FACTORS IN FOOD CHOICE}

Food choices depend not only on availability and preferences, but also on cognitive factors such as knowledge about the benefits and costs associated with eating them. Weight control has been a prominent motive in women's choices for decades, with up to $70 \%$ of women claiming to be 'watching what they eat' in order to regulate their weight. Health and hygiene concerns also have always been salient, most obviously in connection with contamination (food being out-of-date, dropped on the floor, etc.; Rozin \& Fallon, 1980), but also extending to other areas of health and well-being. In a study of college students and their parents (Wardle, 1993), health was rated as more important than any other consideration (taste, cost, convenience) in mothers, and second only to taste in their adult sons and daughters. Among those who rated health highly, there was also evidence for more healthy food choices. In a more recent study (Steptoe et al. 1995) using the newly-developed Food Choice Questionnaire, health motivation in food choice was higher in women than men, and in older adults compared with younger adults. In the 
Family Diet Study, mothers rated health as significantly more important for their children than for themselves.

How and when children come to evaluate foods in health terms, and the role of parental guidance in this process, has attracted little research attention. Dislike as a response to contamination of foods (by contaminants ranging from a leaf to dog faeces) becomes more readily elicited as children get older (Fallon et al. 1984). Disgust and contamination sensitivity were assessed in a sample of adolescents and students and their parents (Davey et al. 1993). Disgust sensitivity proved to be significantly correlated in parents and offspring. Worsley (1990) and Worsley et al. (1984) have used the repertorygrid method to investigate children's concepts of foods. Lists of foods are rated on each of a number of evaluative dimensions (smells nice, good for you, etc.), and the data analysed by principal-components analysis. Graphical representation of the resultant array illustrates how foods are conceptually inter-related. Several studies have indicated an apparent opposition of 'good for you' and 'tastes good', with the expected foods polarizing (e.g. vegetables $v$. chocolate). This method has also been used to identify sex and social-class differences, although the pattern of results had posed some difficulties of interpretation.

Health-related knowledge is transmitted to children at an early age with imprecations of the kind 'eat it up, it's good for you' or 'don't eat any more of those, they're bad for you'. Some evidence suggests that children have a fairly accurate view of which foods are good and bad for them. In a study of 492 secondary schoolchildren (aged 11-16 years), a range of foods was evaluated in terms of whether they should be increased, decreased or unchanged for a healthy diet (Lund et al. 1990). Most children accurately proposed decreasing consumption of whole milk $(63 \%)$ and increasing vegetables $(68 \%)$, brown bread $(70 \%)$ and fruit intake $(74 \%)$. However, they were divided on their evaluation of many other foods, including skimmed milk, butter, red meat, cheese, white bread and breakfast cereals.

Studies of children's food knowledge have focused principally on macronutrient content of foods or macronutrient-disease relationships. Data from 12- and 14-year-old Danish children has shown a reasonable awareness of fat, sugar and fibre in foods (Osler \& Hansen, 1993). Nutritional knowledge, also, was assessed in 5116 American schoolchildren as part of the baseline assessment for a school health promotion programme (Resnicow \& Reinhardt, 1991). A substantial proportion of children endorsed links between fibre and both cancer and heart disease, and between fat and heart disease, but knowledge of macronutrient content of foods was patchy. Few of the younger children were very accurate in saying which common foods were high in fat, fibre or sugar, although the majority thought fruit and vegetables were 'good for you', along with cheese and wholemeal bread. Not many children rated chocolate, fries or ice cream as 'good for you'. Clearly, therefore, these children had some idea that different foods have different health effects, and many have picked up a reasonably-adequate understanding of which foods are healthiest.

What exactly children might mean by healthy, and how they might suppose that foods enact these health-modifying effects has not been investigated. Natapoff's (1978) standardized interviews with 12-year-old children enquired, among other things, what health means and the answers reflected both the state of health itself and associated practices. Specific health practices (eating vegetables, taking exercise, keeping clean) were mentioned more by younger children than by older children. It has been argued 
that over the pre-adolescent years, children develop models of health and illness which are more or less stable and resistant to health education. If so, attention to health cognition in these early years would be an important element of health promotion. In another study of 5 and 9 year olds (Bird \& Podmore, 1990), children were asked about strategies for preventing a number of diseases (including colds and heart attacks), as well as 'staying well'. Most of the young children thought that there were strategies to stay well and avoid colds, although fewer than one-third thought that heart attacks could be avoided. The most favoured strategy for staying healthy and avoiding heart attacks was to eat well.

So far as food choice is concerned, the question is whether and when children use healthiness considerations when they select foods to eat. Michela \& Contento (1986) related children's frequency of consumption of foods to their evaluations of the same foods (good for me, makes me fat, I like to eat it, costs a lot, etc.). Within-child correlations between ratings and consumption frequency across foods were used to develop a profile of food-choice motivations. A child who has a healthful basis of food choice would show a positive relationship between 'good for me' and consumption, a taste-motivated child would have high correlations between 'I like it' and consumption. Cluster analysis was used to classify children into groups based on their profile of food-choice motives. Health orientation was marginally associated with a better diet, based on a $24 \mathrm{~h}$ recall, while taste orientation was more common among children with a moderate or poor diet. However, in the Family Diet Study, children's own ratings of the importance of health in food choice was unrelated to fat or sugar in their diet diaries.

Few, if any, studies have evaluated parent-child similarities in cognitive aspects of food choice, i.e. addressed the question of whether nutritionally-knowledgeable parents have nutritionally-knowledgeable children and health-conscious parents have healthconscious children. Data from the Family Diet Study showed significant parent-child correlations for macronutrient knowledge and for evaluation of the 'healthiness' of individual foods. That children are influenced by their parents, albeit transiently, was illustrated in a novel methodology used by Klesges et al. (1991) to evaluate food choices of young children. Each child was taken to a cafeteria and asked to select a tray of food for lunch. The food was then replaced and they were asked to select again, but told that their mother (who was nearby) would see their selection. Finally, the mother was invited to modify the lunch tray to generate a meal that she would allow the child to eat. The nutritional quality of each lunch tray was the dependent variable. Relative to the free-choice condition, children anticipating maternal monitoring made a selection with substantially less sugar (163 v. $1276 \mathrm{~kJ} ; 39$ v. $305 \mathrm{kcal})$, but there were no other differences in individual macronutrients. Mothers' scrutiny resulted in a further reduction in total energy, saturated fat and $\mathrm{Na}$.

Transgenerational transmission of health attitudes has been almost totally ignored. Among the few exceptions has been Bush \& Ianotti's (1990) work on attitudes to medication use in which they noted comparatively low levels of parent-child similarity in their work on attitudes regarding acquired immune deficiency syndrome (AIDS). McElreath \& Roberts (1992) found that parents' attitudes were a significant predictor of their child's attitude to AIDS. Unfortunately, this effect was not replicated with another attitude measure (Sigelman, 1993), but there was evidence for parent-child similarity in belief in 'AIDS myths'. Whether similar 'food myths' might be transmitted from parent to child has yet to be explored. A study on obesity, which included measures of attitudes 
towards child-feeding among college women and their parents (Rogers et al. 1980), showed a degree of concordance on the use of food as a punishment (i.e. withholding food $(r 0.20)$ and for soothing $(r 0.15)$ but not for the other two attitudinal items. In the Family Diet Study, parents' and children's ratings of the importance of health in food choices were unrelated. Family similarity in change in attitudes was evaluated in part of the San Diego Family Health Project (Patterson et al. 1989), where changes in knowledge of dietary health behaviour and perceived self-efficacy was evaluated in ninety family pairs in the intervention condition. Modest changes in knowledge, behaviour and risk factors were found, with significant parent-child concordance in behaviour change, but there was little or no concordance in knowledge or self-efficacy change. Recent interest in the genetic contribution to attitudes, once seen as a strictly environmental domain, has produced a raft of studies on familial resemblances (Tesser, 1993), but the health domain has rarely been included in this broad-based attitude research.

In support of the positive effect of parents' efforts to give their children a good diet is the deterioration in dietary quality which is noted when children leave home and go to college. Lau et al. (1990) collected data from college students before they came to college and each year for 3 years. Reductions in healthy food choices, and increases in meals skipped were recorded along with reduction in ratings of the value of healthy eating. However, there was some evidence for what Lau et al. (1990) termed the 'enduring family socialization effect'. Parental health practices and beliefs (reported by parents at baseline), as well as explicit training by parents, were significant predictors of their children's beliefs.

Parental attitudes must certainly affect their children indirectly through the foods purchased for and served in the household, thereby also influencing the children's exposure and, hence, perhaps their habits and preferences. This is the mode of influence which is assumed in much parent-targeted family health promotion. Contento et al. (1993) found a relationship between mothers' health motivation and the quality of children's diets. In the Family Diet Study, there was also a significant relationship between mothers' ratings of the importance of health in food choices and their child's food intake. Some of the literature on social-class differences also suggests a link; higher-social-class mothers reporting more health-motivated food planning while lower social status is associated with compliance with family taste preferences.

Another slant on the relationship between parents, children and food is given by evaluating dietary differences between families with and without children. Data from the UK National Food Survey (National Food Survey Committee, 1991) suggests that brown bread consumption is lower in households with children. Data from North America also showed poorer diets in families with children (Emmons et al. 1995). Clearly the direction of causation cannot be established from these studies, but given that it is unlikely that a good diet compromises fertility, the most likely explanation is that pressure from children, combined with time and money constraints in a household with children, promotes the purchase of convenience foods which are attractive to children.

\section{PARENTAL STRATEGIES IN CHILD FEEDING}

The other way in which parental influences on children's diets have been explored is to investigate the problems that parents identify in feeding children healthy foods and the 
strategies that they adopt to overcome them. Much of this research is qualitative but certain issues recur. One particular issue is that women accept the role of responsibility for nutrition (Schafer \& Schafer, 1989). A second is that children dislike some of the foods that mothers would like them to eat often resulting in refusal and family arguments. Conversely, children like and request foods such as sweets or cakes, which parents try to limit, and the countless supermarket tantrums that can be observed attest to the difficulties caused by denying children these attractive and well marketed products. As part of a study of women's roles in feeding their families in relation to their care for their own nutritional health, Devine \& Olson (1992) interviewed small samples of women with young children. These women accepted the 'care taking' role, including trying to get their children to eat well. They also took on a 'teaching' role, informing children about good nutrition and monitoring healthy choices. However, in conflict with these roles was the 'peacekeeping' role, and keeping the peace at meals meant compromises over what the children ate. In the group with older children, complaints from children about health-promoting foods became more prominent and mothers reported 'shutting their eyes' to what the children ate. In the Family Diet Study, mothers consistently described difficulty in persuading their children to eat enough vegetables and fewer sweets and crisps, and many were pessimistic about their chances of success in the future.

Parental strategies to regulate children's food intake have been studied in a number of settings, including both interviews and observation. Most attention is given to methods used by mothers to encourage consumption of disliked or refused foods where parents (usually mothers) report a restricted range of strategies including persuasive argument, (eat it up, it will do you good), contracting for a reduced amount (OK, just eat half then), and promises of reward or punishment (if you eat it up you can have dessert but if you don't eat it you can't). However, evaluating the effectiveness of these strategies in the light of psychological research suggests that they are not likely to be very successful. Rational arguments about health benefits may be effective in the short-term, but in the longer term, problems will develop if children experience consistent associations between their own dislike and their mother's health eulogies (perhaps they learn that things that are good for you don't taste very nice). In a recent study of our own, presenting the same novel drink with or without a 'healthy' label produced lower ratings of liking in the healthy condition (Wardle \& Huon, unpublished results). Negotiations concerning the amount to be eaten could reinforce complaints since the children are effectively rewarded for complaining by the reduced dose of the disliked food (i.e. less spinach). It has also been argued that extrinsic rewards (if you do X you can have $\mathrm{Y}$ ) can result in lower intrinsic reinforcement. Birch et al. (1984) showed that when children consumed foods in order to obtain rewards, preferences for those foods declined relative to control foods with equal exposure. Alternative strategies such as peer modelling, gradual exposure to the taste through strategic food combinations, provision of less-liked foods in minutely small amounts are less often used by parents, though they might be more effective. However, one practical problem for parents is likely to be the vast range of food types which fall into the categories of 'liked a lot by child but disapproved of by mother' and 'disliked by child but approved of by mother'. Consequently continuing effort would be required to persuade the child to accept less-preferred foods over more-preferred foods resulting in child feeding being hard labour. 


\section{CONCLUSIONS}

The childhood years and the family context are widely assumed to be crucial in the establishment of healthy dietary habits. However, data on the processes whereby parents influence their children's dietary habits are sparse. Healthier choices at one stage in life are associated with healthier choices at a later stage (Lau et al. 1990; Kelder et al. 1994), but this minimal persistence is set in the context of considerable change in eating habits between childhood and adulthood, as well as changes in the population's eating habits over time. Parents and children share comparatively few likes and dislikes and most deliberate parental strategies for influencing their children's food choices seem doomed to failure. In view of the recognition that diet can make a substantial contribution to variation in health and disease, and that making healthy food choices is, in the current political climate, likely to be left to individuals, then understanding how food choices and food attitudes develop is of critical significance.

\section{REFERENCES}

Basch, C. E., Shea, S. \& Zybert, P. (1994). The reproducibility of data from a food frequency questionnaire among low-income Latina mothers and their children. American Journal of Public Health 84, 861-864.

Berenson, G. S., Srinivasan, S. R., Hunter, S. M., Nicklas, T. A., Freedman, D. S., Shear, C. L. \& Webber, L. S. (1989). Risk factors in early life as predictors of adult heart disease: The Bogalusa Heart Study. American Journal of the Medical Sciences 298, 141-151.

Birch, L. L. (1980). The relationship between children's food preferences and those of their parents. Journal of Nutrition Education 12, 14-18.

Birch, L. L. (1987). Children's food preferences: developmental patterns and environmental influences. Annals of Child Development 4, 171-208.

Birch, L. L., McPhee, L., Steinberg, L. \& Sullivan, S. (1990). Conditioned flavor preferences in young children. Physiology and Behavior 47, 501-505.

Birch, L. L. \& Marlin, D. W. (1982). I don't like it: I never tried it: effects of exposure on two-year-old children's food preferences. Appetite 3, 353-360.

Birch, L. L., Marlin, D. W. \& Rotter, J. (1984). Eating as the 'means' activity in a contingency: effects on young children's food preference. Child Development 55, 432-439.

Bird, J. E. \& Podmore, V. N. (1990). Children's understanding of health and illness. Psychology and Health 4, $175-185$.

Bryan, M. S. \& Lowenberg, M. E. (1958). The father's influence on young children's food preferences. Journal of the American Dietetic Association 34, 30-35.

Bush, P. J. \& Iannotti, R. J. (1990). A children's Health Belief Model. Medical Care 28, 69-86.

Committee on Medical Aspects of Food Policy (1989). The Diets of British Schoolchildren. London: H.M. Stationery Office.

Contento, I. R., Basch, C., Shea, S., Gutin, B., Zybert, P., Michela, J. L. \& Rips, J. (1993). Relationship of mothers' food choice criteria to food intake of preschool children: identification of family subgroups. Health Education Quarterly 20, 243-259.

Davey, G. C. L., Forster, L. \& Mayhew, G. (1993). Familial resemblances in disgust sensitivity and animal phobias. Behavior Research and Therapy 31, 41-50.

Devine, C. M. \& Olson, C. M. (1992). Women's perceptions about the way social roles promote or constrain personal nutrition care. Women and Health 19, 79-95.

Emmons, K. M., Cargill, B. R., Linnan, L. \& Abrams, D. B. (1995). The impact of children on adults' health promoting behaviors. Annals of Behavioral Medicine 17, Suppl., S079.

Fallon, A. E., Rozin, P. \& Pliner, P. (1984). The child's conception of food: the development of food rejections with special reference to disgust and contamination sensitivity. Child Development 55, 566-575.

Freedman, D. S., Shear, C. L., Burke, G. L., Srinivasan, S. R., Webber, L. S., Harsha, D. W. \& Berenson, G. S. (1987). Persistence of juvenile-onset obesity over eight years: The Bogalusa Heart Study. American Journal of Public Health 77, 588-592. 
Garn, S. M. (1986). Family-line and socioeconomic factors in fatness and obesity. Nutrition Reviews 44, 381-386.

Garn, S. M., Cole, P. E. \& Bailey, S. M. (1979). Living together as a factor in family-line resemblances. Human Biology 51, 565-587.

Gregory, J., Collins, D. L., Davies, P. S. W., Hughes, J. M. \& Clarke, P. C. (1995). National Diet and Nutrition Survey: Children aged 1/2 to 4t/2. London: H.M. Stationery Office.

Havas, S., Heimendinger, J., Reynolds, K., Baranowski, T., Nicklas, T. A., Bishop, D., Buller, D., Sorensen, G., Beresford, S. A. A., Cowan, A. \& Damron, D. (1994). 5 a day for better health: a new research initiative. Journal of the American Dietetic Association 94, 32-36.

Johnson, S. L., McPhee, L: \& Birch, L. L. (1991). Conditioned preferences: young children prefer flavors associated with high dietary fat. Physiology and Behavior 50, 1245-1251.

Kelder, S. H., Perry, C. L., Klepp, K.-I. \& Lytle, L. L. (1994). Longitudinal tracking of adolescent smoking, physical activity, and food choice behaviors. American Journal of Public Health 84, 1121-1126.

Khoury, P., Morrison, J, A., Laskarzewski, P. M. \& Glueck, C. J. (1983). Parent-offspring and sibling body mass index associations during and after sharing of common household environments: The Princeton School District Family Study. Metabolism 32, 82-89.

Kimm, S. Y. S., Gergen, P. J., Malloy, M., Dresser, C. \& Carrol, M. (1990). Dietary patterns of US children: implications for disease prevention. Preventive Medicine 19, 432-442.

Klesges, R. C., Stein, R. J., Eck, L. H., Isbell, T. R. \& Klesges, L. M. (1991). Parental influence on food selection in young children and its relationships to childhood obesity. American Journal of Clinical Nutrition $53,859-864$.

Laskarzewski, P., Morrison, J. A., Khoury, P., Kelly, K., Glatfelter, L., Larsen, R. \& Glueck, C. J. (1980). Parent-child nutrient intake interrelationships in school children ages 6 to 19: The Princeton School District Study. American Journal of Clinical Nutrition 33, 2350-2355.

Lau, R., Quadrel, M. J. \& Hartman, K. A. (1990). Development and change of young adults' preventive health beliefs and behavior: influence from parents and peers. Journal of Health and Social Behavior 31, 240-259.

Lauer, R. M. \& Clarke, W. R. (1990). Use of cholesterol measurements in childhood for the prediction of adult hypercholesterolemia. Journal of the American Medical Association 264, 3034-3038.

Lund, B. K., Gregson, K., Neale, R. I. \& Tilston, C. H. (1990). Dietary awareness of children: specific food components. British Food Joumal 2, 23-27.

McElreath, L. H. \& Roberts, M. C. (1992). Perceptions of acquired immune deficiency syndrome by children and their parents. Journal of Pediatric Psychology 17, 477-490.

Michela, J. L. \& Contento, I. R. (1986). Cognitive, motivational, social and environmental influences on children's food choices. Health Psychology 5, 209-230.

Moller, J. H., Taubert, K. A., Allen, H. D., Clark, E. B. \& Lauer, R. M. (1994). Cardiovascular health and disease in children: current status. Circulation 89, 923-930.

Morrison, J. A., Kelly, K., Horvitz, R., Khoury, P., Laskarzewski, P. M., Mellies, M. J. \& Glueck, C. J. (1982). Parent-offspring and sibling lipid and lipoprotein associations during and after sharing of household environments: The Princeton School District Family Study. Metabolism 31, 158-166.

Morrison, J. A., Payne, G., Barton, B. A., Khoury, P. R. \& Crawford, P. (1994). Mother-daughter correlations of obesity and cardiovascular disease risk factors in black and white households: The NHLBI Growth and Health Study. American Journal of Public Health 84, 1761-1767.

Natapoff, J. N. (1978). Children's views of health: a developmental study. American Journal of Public Health 68, $995-1000$.

National Food Survey Committee (1991). Household Food Consumption and Expenditure 1990. London: H.M. Stationery Office.

Newman, W. P. III, Freedman, D. S., Voors, A. W., Gard, P. D., Srinivasan, S. R., Cresanta, J. L., Williamson, G. D., Webber, L. S. \& Berenson, G. S. (1986). Relation of serum lipoprotein levels and systolic blood pressure to early atherosclerosis: the Bogalusa Heart Study. New England Journal of Medicine 314, 138-144.

Oliveria, S. A., Ellison, R. C., Moore, L. L., Gillman, M. W., Garrahie, E. J. \& Singer, M. R. (1992). Parent-child relationships in nutrient intake: the Framingham Children's Study. American Journal of Clinical Nutrition 56, 593-598.

Osler, M. \& Hansen, E. T. (1993). Dietary knowledge and behaviour among schoolchildren in Copenhagen, Denmark. Scandinavian Journal of Social Medicine 2, 135-140. 
Patterson, T. L., Sallis, J. F., Nader, P. R., Kaplan, R. M., Rupp, J. W., Atkins, C. J. \& Senn, K. L. (1989). Familial similarities of changes in cognitive, behavioral, and physiological variables in a cardiovascular health promotion program. Journal of Pediatric Psychology 14, 277-292.

Pérusse, L., Tremblay, A., Leblanc, C., Cloninger, R., Reich, T., Rice, J. \& Bouchard, C. (1988). Familial resemblance in energy intake: contribution of genetic and environmental factors. American Journal of Clinical Nutrition 47, 629-635.

Pliner, P. (1983). Family resemblance in food preferences. Journal of Nutrition Education 15, 137-140.

Pliner, P. \& Pelchat, M. L. (1986). Similarities in food preferences between children and their siblings and parents. Appetite 7, 333-342.

Porkka, K. V. K., Viikari, J. S. A., Taimela, S., Dahl, M. \& Åkerblom, H. K. (1994). Tracking and predictiveness of serum lipid and lipoprotein measurements in childhood: a 12-year follow-up. American Journal of Epidemiology 140, 1096-1110.

Resnicow, K. \& Reinhardt, J. (1991). What do children know about fat, fibre, and cholesterol? A survey of 5,116 primary and secondary school students. Journal of Nutrition Education 23, 65-71.

Rogers, C. S., Canady, H. \& Wentworth, J. (1980). Obesity, child-feeding attitudes, and reactive eating: an intergenerational study. Home Economics Research Journal 8, 173-183.

Rozin, P. (1984). The acquisition of food habits and preferences. In Behavioral Health: A Handbook of Health Enhancement and Disease Prevention, pp. 590-607 [J. D. Matarazzo, S. M. Weiss, J. A. Herd, N. E. Miller and S. M. Weiss, editors]. New York: Wiley.

Rozin, P. (1990). The importance of social factors in understanding the acquisition of food habits. In Taste, Experience and Feeding, pp. 255-269 [E. D. Capaldi and T. L. Powley, editors]. Washington, DC: American Psychological Association.

Rozin, P. (1991). Family resemblance in food and other domains: the family paradox and the role of parental congruence. Appetite 16, 93-102.

Rozin, P. \& Fallon, A. (1980). The psychological categorization of foods and non-foods: a preliminary taxonomy of food rejections. Appetite 1, 193-201.

Sackett, D. L., Anderson, G. D., Milner, R., Feinleib, M. \& Kannel, W. B. (1975). Concordance for coronary risk factors among spouses. Circulation 52, 589-595.

Schafer, R. B. \& Schafer, E. (1989). Relationship between gender and food roles in the family. Journal of Nutrition Education 21, 119-126.

Sigelman, C. K. (1993). Parents' contributions to knowledge and attitudes regarding AIDS. Journal of Pediatric Psychology 18, 221-235.

Steptoe, A., Pollard, T. \& Wardle, J. (1995). The development of a measure of the factors underlying the selection of food: The Food Choice Questionnaire. Appetite (In the Press.)

Tesser, A. (1993). The importance of heritability in psychological research: the case of attitudes. Psychological Review 100, 129-142.

Thompson, F. E. \& Dennison, B. A. (1994). Dietary sources of fats and cholesterol in US children aged 2 through 5 years. American Journal of Public Health 84, 799-806.

Tiret, L., Ducimetiere, P., Andre, J. L., Gueguen, R., Herbeth, B., Spyckerelle, Y., Rakotovao, R. \& Cambien, F. (1991). Family resemblance in body circumferences and their ratios: the Nancy family study. Annals of Human Biology 18, 259-271.

Vogler, G. P., Sørensen, T. I. A., Stunkard, A. J., Srinivasan, M. R. \& Rao, D. C. (1995). Influences of genes and shared family environment on adult body mass index assessed in an adoption study by a comprehensive path model. International Journal of Obesity 19, 40-45.

Wardle, J. (1993). Food choices and health evaluation. Psychology and Health 8, 65-75.

Weidner, G., Archer, S., Healy, B. \& Matarazzo, J. D. (1985). Family consumption of low fat foods: stated preference versus actual consumption. Journal of Applied Social Psychology 15, 773-779.

Worsley, A. (1980). Thought for food: investigations of cognitive aspects of food. Ecology of Food and Nutrition 9, 65-80.

Worsley, A., Baghurst, P., Worsley, A. J., Coonan, W. \& Peters, M. (1984). Australian ten year olds' perceptions of food: I. sex differences. Ecology of Food and Nutrition 15, 231-246. 